\title{
FOUR-POINT BENDING TESTS OF DOUBLE LAMINATED GLASS PANELS WITH EVA INTERLAYER IN VARIOUS LOADING RATES
}

\author{
T. Hána*, M. Eliášová ${ }^{* *}$, Z. Sokol ${ }^{* * *}$, M. Vokáćc***
}

\begin{abstract}
Current architecture tends to use glass as a load-bearing material thus glass beams, panels, columns or even stairs may be found. These members are mostly made of laminated glass with polymeric interlayer. Laminated glass performs good response in accidental situation because glass fragments stay attached to the interlayer and do not cause harmful injuries. Polymeric interlayer is able to ensure the transfer of shear forces between the individual panes in a perpendicularly loaded panel. This transfer depends on the shear stiffness of the interlayer as a time and temperature-dependent parameter which is not usually available. Civil engineers thus neglect this stiffness to stay on a safe side. This paper shows the experimental data gained from four-point bending tests of double-laminated glass panels with EVA based interlayer (Evalam 80/120 ${ }^{\circledR}$ ) loaded in three various loading rates and illustrates the influence of the loading rate on the stress-state and vertical deflections of a panel. The analogy with shear stiffness of another EVA based interlayer $\left(\right.$ Evasafe $\left.^{\circledR}\right)$ is further commented. All experiments were performed at CTU in Prague.
\end{abstract}

Keywords: Laminated Glass, Polymeric Interlayer, Normal Stress, Vertical Deflection, Loading Rate.

\section{Introduction}

Performance of perpendicularly loaded laminated glass panels is the scope of an intensive research (Molnár et al. 2012) as well as its performance in a post-breakage phase. Stress-state and deflections of a panel depend on the shear stiffness of polymeric interlayer. Because polymers are viscoelastic materials whose mechanical properties are time and temperature-dependent, these must be experimentally verified. There have been several efforts made to find the shear stiffness of widely used PVB and EVA interlayers on small-scale specimens (Kuntsche et al. 2015; Hána et al. 2017) using quasi-static tests or dynamic tests in various temperatures. Static loading enables to determine the initial shear stiffness, dynamic tests then enable to predict the shear stiffness of tested interlayer in time domain. To verify small-scale experiments, large-scale four-point bending tests of double-laminated glass panels are appropriate. This paper describes performed experiments at CTU in Prague and introduces the experimental data, particularly normal stresses and vertical deflections at the mid-span cross section obtained from four-point bending tests of doublelaminated heat toughened glass panels laminated with EVA (Evalam 80/120 ${ }^{\circledR}$ ) interlayer. Bending tests were executed at three various loading rates. The analogy of experimental results with published initial shear stiffness of another EVA based interlayer (Evasafe ${ }^{\circledR}$ ) obtained from quasi-static tests is further commented. Experimentally verified shear stiffness of polymeric interlayers used in laminated glass enables to capture the shear coupling of glass panes more precisely and enables to design more economical and simultaneously safe glass structures in practice.

\footnotetext{
Ing. Tomáš Hána: Klokner Institute, CTU in Prague, Šolínova 7; 166 29, Prague; CZ, tomas.hana@ fsv.cvut.cz

** Assoc. Prof. Martina Eliášová, CSc.: Department of Steel and Timber Structures, Faculty of Civil Engineering CTU in Prague, Thákurova 7; 166 29, Prague; CZ, eliasova@ fsv.cvut.cz

*** Ing. Zdeněk Sokol, Ph.D.: Department of Steel and Timber Structures, Faculty of Civil Engineering CTU in Prague, Thákurova 7; 166 29, Prague; CZ, sokol@fsv.cvut.cz

**** Ing. Miroslav Vokáč, Ph.D.: Klokner Institute, CTU in Prague, Šolínova 7; 166 29, Prague; CZ, Miroslav.Vokac@ cvut.cz
} 


\section{Experimental program}

There were totally nine double-laminated heat toughened glass panels with EVA (Evalam 80/120 ${ }^{\circledR}$ ) interlayer tested in four-point bending tests. Static schema of four-point bending test, nominal dimensions of the specimen $1100 \times 360 \mathrm{~mm}$, and placing the specimen on the supports through rubber pads were in accordance with ČSN EN 1288-3 (ČSN EN 1288-3 2001). Position of the specimen in MTS loading device is displayed in Fig. 1. Nominal thickness of one glass pane was $10 \mathrm{~mm}$ and of the interlayer it was $0.76 \mathrm{~mm}$. To measure the normal stress at the mid-span cross section, there were totally six strain gauges LY 1110/120 attached to the glass surface - three gauges in tension (lower surface-lower glass pane) and three gauges in compression (upper surface-upper glass pane) as shown in Fig. 2. Vertical deflection at the midspan was measured by two displacement sensors (I and II) and the mutual horizontal displacement of the glass panes above the support was measured by four potentiometric linear transducers MMR 1011 marked as $\mathrm{T}_{1}-\mathrm{T}_{4}$. Positions of these sensors are shown in Fig. 3. The tests were performed in MTS loading device with maximum loading capacity $100 \mathrm{kN}$. The loading was displacement controlled with the cross-head speed of $2.0 \mathrm{~mm} / \mathrm{min}, 0.5 \mathrm{~mm} / \mathrm{min}$, or $0.125 \mathrm{~mm} / \mathrm{min}$ which were kept constant. The loading phase was terminated at the lower glass pane breakage when the glass tensile strength was exceeded. Denomination of testing specimens, their loading rates, composition and measured temperature are summarized in Tab. 1.
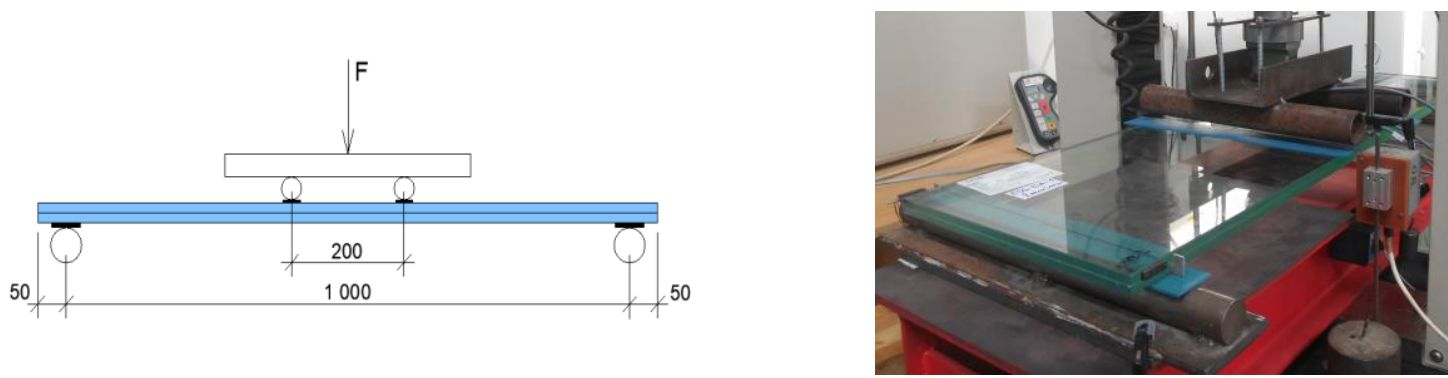

Fig. 1: Static schema of four-point bending test and position of testing specimen in MTS device.
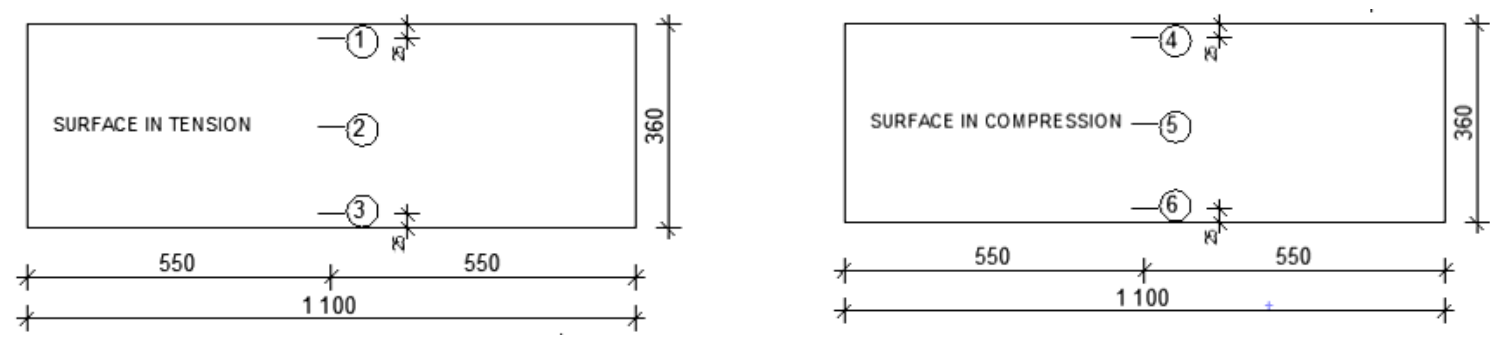

Fig. 2: Positions of strain gauges on the test specimen, SG1-SG6.
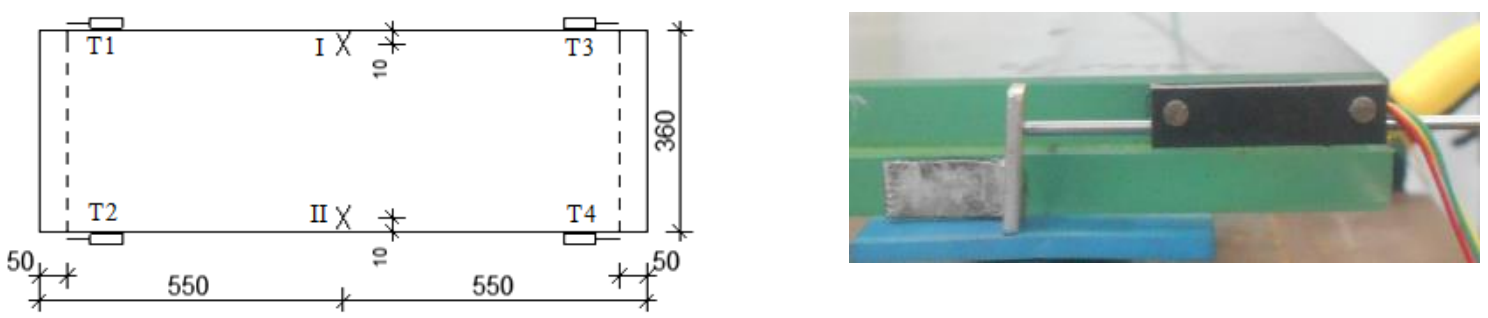

Fig. 3: Positions of vertical displacement sensors I, II and of linear transducers $T_{1}-T_{4}$ on the specimen.

Tab. 1: Denomination, loading rates, temperature, and composition of testing specimens.

\begin{tabular}{cccccccc}
\hline $\begin{array}{c}\text { Number } \\
\text { of } \\
\text { specimen }\end{array}$ & $\begin{array}{c}\text { Loading } \\
\text { rate } \\
\mathbf{m m} / \mathbf{m i n}]\end{array}$ & $\begin{array}{c}\text { Tempera- } \\
\text { ture } \\
{\left[{ }^{\circ} \mathbf{C}\right]}\end{array}$ & $\begin{array}{c}\text { Composition } \\
\text { of } \\
\text { specimen }\end{array}$ & $\begin{array}{c}\text { Number } \\
\text { of } \\
\text { specimen }\end{array}$ & $\begin{array}{c}\text { Loading } \\
\text { rate } \\
{[\mathbf{m m} / \mathbf{m i n}]}\end{array}$ & $\begin{array}{c}\text { Tempera- } \\
\text { ture } \\
{\left[{ }^{\circ} \mathbf{C}\right]}\end{array}$ & $\begin{array}{c}\text { Composition } \\
\text { of } \\
\text { specimen }\end{array}$ \\
\hline 1 & 2.0 & 25 & $10.10 .2 \mathrm{EVA}$ & 6 & 0.5 & 24 & $10.10 .2 \mathrm{EVA}$ \\
\hline 2 & 2.0 & 25 & $10.10 .2 \mathrm{EVA}$ & 7 & 0.125 & 28 & $10.10 .2 \mathrm{EVA}$ \\
\hline 3 & 2.0 & 25 & $10.10 .2 \mathrm{EVA}$ & 8 & 0.125 & 28 & $10.10 .2 \mathrm{EVA}$ \\
\hline 4 & 0.5 & 28 & $10.10 .2 \mathrm{EVA}$ & 9 & 0.125 & 28 & $10.10 .2 \mathrm{EVA}$ \\
\hline 5 & 0.5 & 28 & $10.10 .2 \mathrm{EVA}$ & & & & \\
\hline
\end{tabular}




\section{Results}

The following paragraph refers to the experimental data. Charts in Fig. 4 show force-stress (SG1) and forcedeflection relationships of representative specimens 1,4 , and 7 . All relations are linear. It should be noted that the temperature of the specimen 1 was about $3{ }^{\circ} \mathrm{C}$ lower in comparison with the specimens 4 and 7 . Molecular movement and relaxation behavior of polymeric materials are thermally and loading-rate activated processes (Ferry 1980). Higher loading rate and lower temperature of specimen 1 in comparison with specimens 4 and 7 thus denotes higher shear stiffness of Evalam which resulted into more favorable normal stress and deflections. Force-stress and force-deflection relations of specimens 4 and 7 are almost identical, thus their various loading rate does not meaningly influence measured values. It could be generally said that all measured experimental relations are temperature and loading rate sensitive which must be caused by various shear stiffness of Evalam. This statement is supported by quasi-static tests of another EVA based interlayer $\left(\right.$ Evasafe $^{\circledR}$ ) whose initial shear stiffness modulus also reacts to the temperature and the rate of the load (Hána et al. 2017). The order of relationships in Fig. 4 is confirmed by the values of measured mutual horizontal displacement of glass panes above the support (transducer $\mathrm{T}_{3}$ ) in Fig. 5a. Specimen 1 achieved considerably lower values of this quantity in the entire loading phase than specimens 4 and 7 did, which again proves its stiffer Evalam interlayer. Other transducers measured these relations in the same manner. Normal stress of specimen 7 was not uniformly distributed along the width of the cross section at the moment of the lower glass pane breakage, see Fig. 5b. The ratios of the normal stresses at the lower surface/upper surface measured by opposite strain gauges were up to $3.1 \%$. This detection means that both glass panes were almost fully-shear coupled.
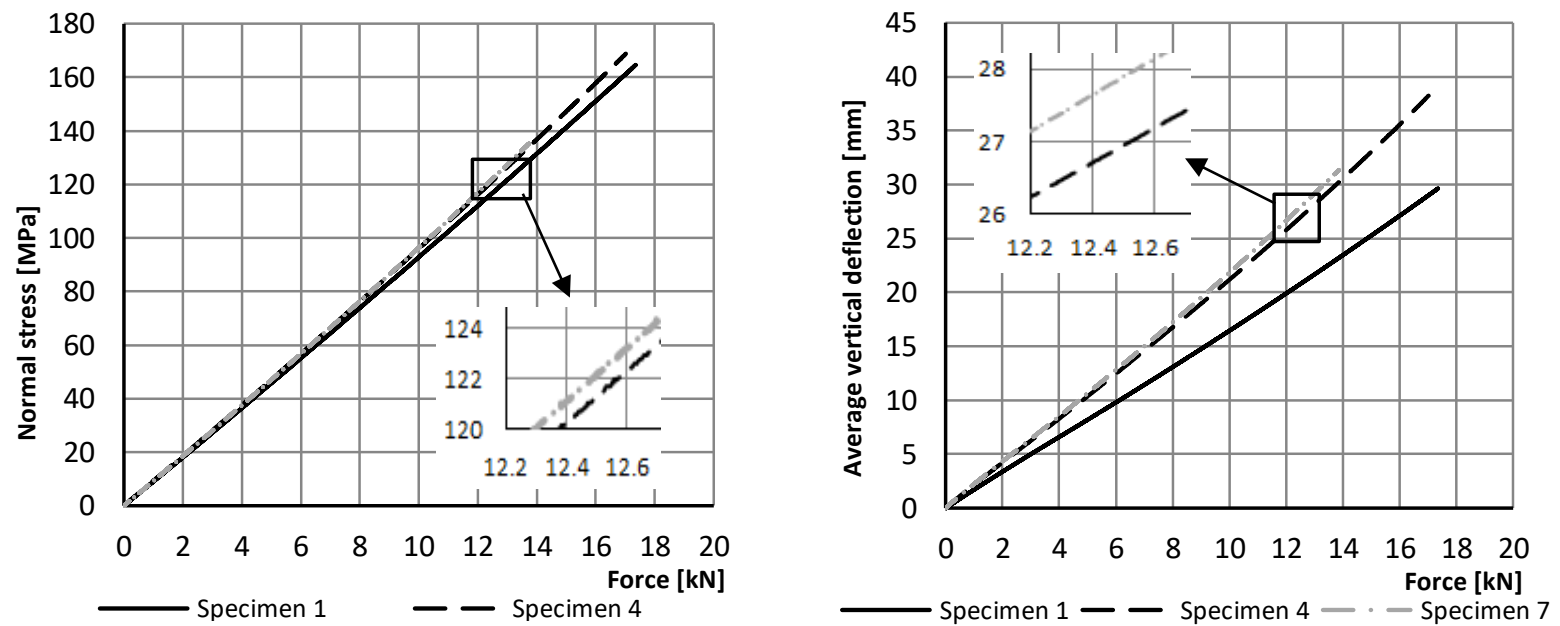

Fig. 4: Force-stress relations measured by strain gauge number 1 and force-vertical deflection relations of specimens 1,4 , and 7.
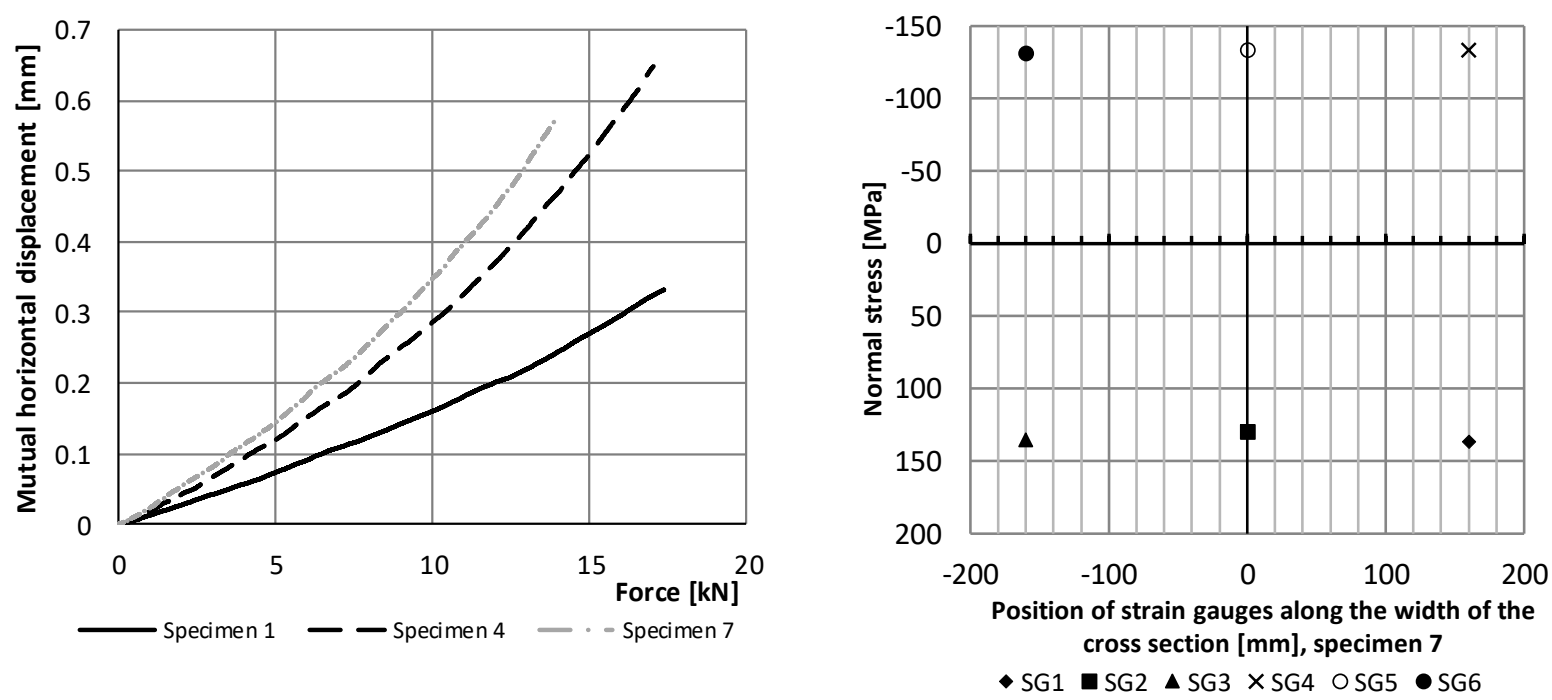

Fig. 5: a) Mutual displacement $T_{3}$ of glass panes above the support of specimens 1, 4, and 7; b) normal stress along the cross section at the lower glass pane breakage of the specimen number 7. 
To give the numerical example of the aforementioned relations, all measured data of all tested specimens are summarized in Tab. 2 for the value of the applied force $14 \mathrm{kN}$. Specimens loaded with the loading rate $2.0 \mathrm{~mm} / \mathrm{min}$ attain in average about $4 \mathrm{MPa}$ lower values of normal stress, about $5 \mathrm{~mm}$ lower vertical deflections, and about $0.2 \mathrm{~mm}$ lower values of glass panes mutual horizontal displacement than those loaded with the rate of $0.5 \mathrm{~mm} / \mathrm{min}$. To mention the average differences between the specimens loaded with the rate of $2.0 \mathrm{~mm} / \mathrm{min}$ and $0.125 \mathrm{~mm} / \mathrm{min}$, these are $5 \mathrm{MPa}, 7.5 \mathrm{~mm}$, and $0.3 \mathrm{~mm}$. This statement is supported by measured relations displayed in Fig. 4 and in Fig. 5. In spite of the fact that specimens 4, 5, and 6 were loaded with identical loding rate $0.5 \mathrm{~mm} / \mathrm{min}$, the specimen 6 attained, in comparison to 4 and 5 , considerably lower values of all measured quantities, as one can see in Tab. 2. This phenomenon is attributed to the influence of temperature, see Tab. 1.

Tab. 2: Normal stress measured by SG1, vertical deflections and mutual horizontal displacement of glass panes $T_{3}$ for the value of the applied force $14.0 \mathrm{kN}$

\begin{tabular}{ccccc}
\hline \multirow{2}{*}{ Specimen } & Stress (SG1) & Deflection I & Deflection II & Mutual displacement $\mathbf{T}_{\mathbf{3}}$ \\
\cline { 2 - 5 } & {$[\mathbf{M P a}]$} & {$[\mathbf{m m}]$} & {$[\mathbf{m m}]$} & {$[\mathbf{m m}]$} \\
\hline 1 & 131.5 & 23.2 & 23.7 & 0.245 \\
\hline 2 & 130.6 & 23.3 & 23.5 & 0.261 \\
\hline 3 & 131.4 & 23.6 & 24.1 & 0.258 \\
\hline 4 & 136.8 & 30.9 & 30.2 & 0.470 \\
\hline 5 & 138.0 & 30.7 & 31.4 & 0.475 \\
\hline 6 & 131.2 & 24.6 & 23.4 & 0.401 \\
\hline 7 & 136.6 & 31.7 & 31.0 & 0.570 \\
\hline 8 & not specified & 32.3 & 32.0 & 0.546 \\
\hline $9 *$ & 129.2 & 29.8 & 29.5 & 0.529 \\
\hline
\end{tabular}

*Data are specified for the applied force of $13 \mathrm{kN}$ as the maximum measured value.

\section{Conclusions}

In this paper, important experimental results concerning displacement controlled four-point bending tests of nine double laminated glass panels loaded in three various loading rates in the range of temperature 24$28{ }^{\circ} \mathrm{C}$ were elaborated. All panels were laminated with Evalam $80 / 120^{\circledR}$ interlayer. Panels loaded with the loading rate $2.0 \mathrm{~mm} / \mathrm{min}$ performed stiffer response resulting into lower values of normal stress, vertical deflections, and mutual horizontal displacement of glass panes above the support at the certain force than those loaded with the rate $0.5 \mathrm{~mm} / \mathrm{min}$ or $0.125 \mathrm{~mm} / \mathrm{min}$. There were not significant differences between measured relations in case of panels loaded at $0.5 \mathrm{~mm} / \mathrm{min}$ and at $0.125 \mathrm{~mm} / \mathrm{min}$ thus shear stiffness of Evalam must have been at these loading rates almost identical. Loading rate and temperature shear stiffness dependence of another EVA based interlayer (Evasafe ${ }^{\circledR}$ ) had been proven by static tests in shear before (Hána et al. 2017). Static and dynamic small-scale loading tests of interlayers in shear enable to predict their shear stiffness but this must be verified by large-scale loading tests to exclude possible size-effects and measurement inaccuracies. This is the way how to extend the use of glass structures in practice.

\section{Acknowledgement}

This research was supported by project MPO TRIO FV10295.

\section{References}

Molnár G., Vigh L.G., Stocker G., and Dunai L.: Finite element analysis of laminated structural glass plates with polyvinylbutyral (PVB) interlayer, R Periodica Polytechnica 56/1, 2012, pp 35-42.

Kuntsche J., Schuster M., Schneider J., and Langer S.: Viscoelastic properties of laminated glass interlayers - Theory and experiments, Glass Performance Days, 2015, pp 143-147.

Hána T., Eliášová M., Machalická K., and Vokáč M.: Determination of PVB and EVA shear stiffness modulus depending on a temperature and loading rate, TZB info, 2018, www.stavba.tzb-info.cz.

ČSN EN 1288-3: Determination of glass tensile strength in bending, Czech Institute for Standardization, 2001.

Ferry J.D.: Viscoelastic properties of polymers, John Wiley \& Sons, 1980, ISBN 0-471-04894-1 